\title{
Introduction to'Risks, Ruptures and Uncertainties: Dealing with Crisis in Asia's Emerging Economies'
}

\author{
Kirsten W. Endres, Max Planck Institute for Social Anthropology, Halle/Saale \\ Maria Six-Hohenbalken, Institute for Social Anthropology, Austrian Academy \\ of Sciences
}

\begin{abstract}
Asia's ongoing economic transformation has created a variety of unexpected ruptures, discontinuities and opportunities in the lives of local citizens across the region. The introduction to this special section of the journal frames the contributions that follow with a brief review of current scholarly discussions regarding the interrelated concepts of crisis, risk and uncertainty. It then provides an overview of the articles in this collection and highlights the ways in which they contribute to an understanding of local responses to, and strategies for coping with, risk and uncertainty as multidimensional, interwoven aspects of their daily lives, guided by social, economic and moral considerations.
\end{abstract}

Keywords: Asia, crisis, risk, rupture, transformation, uncertainty

Risk, uncertainty and crisis are inherent aspects of the human condition - or, to quote from Janet Roitman's recent book Anti-Crisis, they 'characterize the world in which we act' (Roitman 2014: 73). Considering the resilience of Asia's emerging economies in the face of the recent world-wide economic downturn, crisis may not be the first association that comes to mind when thinking of the regional area we refer to as 'Asia.' Yet Asia's ongoing economic transformation and its concomitant (re-)emergence as a major engine of the global economy has been unfolding in very uneven ways across regions and within each society. Whereas the overall levels of, and opportunities for, economic advancement have generally increased, social and economic transformations, political ideologies, structural violation, natural and human-induced disasters and the vicissitudes of the market have, among other factors, led not just to temporary ruptures and discontinuities in the lives of local citizens, but also to prolonged 'conditions in which people (including the state's agents) must improvise with the elements of their social and political technologies and cope with a variety of unexpected disruptions and opportunities' (Greenhouse 2002: 9).

Such conditions, marked by contingency and unpredictability, are commonly seen as characteristic of crises (ibid.). In a systemic sense, 'crisis' can refer to contested 
continuities, including critique; to increased precariousness; to potential demise; as well as to structural innovation and emergence. In its individual, biographical dimension, 'crisis' addresses potential ruptures in personal lives that may relate to economic or sociopolitical aspects as much as to family matters, health-related issues and environmental impacts. Based on anthropological research in a variety of local settings, the contributions to this special section pursue the following questions. How do social agents face, cope with, suffer from, yet also contest, adapt to, use, intervene in, or negotiate moments of crisis? How do they deal with adverse and challenging living conditions? In which ways do crises interact with overall economic, social and spatial transformations? What is the relationship between crises and transnational mobility, deterritorialization, and questions of identity and citizenship? How are crises interpreted and classified in their aftermath, and how do they contribute to the construction of new social imaginaries?

\section{Crisis as Context}

In everyday language, 'crisis' is commonly associated with (human-made or natural) disasters, with social, economic, political or environmental upheaval, with conflict and disruption, or with experiences of trauma, persecution and loss (Roy 2007). In his conceptual history of the term, Reinhart Kosseleck points to the historicity of 'crisis' and its different uses over the centuries until it was transformed into a catchword that 'fit [s] the uncertainties of whatever might be favored at a given time' (Kosseleck 2006: 399). The use of the term 'crisis' in ancient Greek medical lore - referring to a decisive stage in the course of a patient's medical condition at which the ultimate fate of the person, life or death, was determined (ibid.: 360) - has had major repercussions on the connotations with which it is imbued in present-day parlance, indicating a transitional period of 'disorder' that leads either to the restoration of the previous state of affairs or to the creation of a new 'state of normality' (Vigh 2008: 9).

Yet as anthropologist Henrik Vigh (2008) has aptly pointed out in his essay Crisis and Chronicity, such an understanding of crises as temporary disruptions misses the fact that 'a great many people find themselves caught in prolonged crisis rather than merely moving through it' (ibid.: 8). For these people - including 'the chronically ill, the structurally violated, socially marginalized and poor' (ibid.: 7) - crisis has become the norm rather than the exception, a constant condition rather than a temporary abnormity. Vigh therefore proposes to shift the focus of anthropological enquiry from 'placing a given instance of crisis in context' to one that sees 'crisis as context' (ibid: 8 , emphasis in the original). This point is taken up by Roitman (2014: 66) who notes that "crisis is the means to access both the "social" and "experience" because it entails the disclosure of the constitutive conditions of human practice. By this, she does not mean to imply that crisis is something that can be viewed or observed in itself. On the contrary, Roitman (building on Luhmann) points to the (paradoxical) nature of crisis as a 'blind spot that enables the production of knowledge' (ibid.: 39). Or, put differently, 'crisis is not a condition to be observed (loss of meaning, alienation, faulty knowledge); it is an observation that produces meaning' (ibid.). 


\section{Risk and Uncertainty}

Intimately linked to 'crisis' are the interrelated, yet analytically distinct, concepts of risk and uncertainty. While space does not permit us to give a comprehensive overview of the literature on the relationship between these two concepts, a brief clarification seems to be in order. ${ }^{2}$ In his seminal work Risk, Uncertainty and Profit (1964 [1921]: 233), economist Frank Knight holds that:

The practical difference between the two categories, risk and uncertainty, is that in the former the distribution of the outcome in a group of instances is known (either through calculation a priori or from statistics of past experience), while in the case of uncertainty this is not true, the reason being in general that it is impossible to form a group of instances, because the situation dealt with is in a high degree unique.

In other words, Knight distinguished between a 'measurable', or calculable form of indeterminacy (risk), and an incalculable one (uncertainty) (Roitman 2014: 74). Whereas risk entails the likeliness of an unfavourable future outcome (albeit one that can be assessed and managed), uncertainty essentially leaves open the possibility of positive effects and desirable changes. Risk can therefore 'be understood as a framing device which conceptually translates uncertainty from being an open-ended field of unpredicted possibilities into a bounded set of possible consequences' (Boholm 2003: 167).

In her essay on Israeli preparedness for biological threats, such as pandemic flu, Limor Samimian-Darash (2013: 3), drawing on the works of Luhmann, Deleuze and Rabinow, departs from the familiar distinction between risk and uncertainty. Instead she proposes to distinguish between possible uncertainty, deriving from a 'lack of knowledge regarding the realization or nonrealization of a particular possibility' (and as such comparable to risk), and potential uncertainty, deriving 'from a state of virtuality in which various events can emerge simultaneously'. In contrast to the risk society approach (Giddens 1991, 1997; Beck 1992) that narrows the notion of risk to its negative effects, Samimian-Darash's analytical distinction between 'possible uncertainty' and 'potential uncertainty' highlights that uncertainty in fact offers a multitude of future options and opportunities, including favourable ones. Looking at the ways in which social actors and institutions deal with risk and uncertainty thus also provides insights into the ways in which the future is conceptualized and anticipated (F. von Benda-Beckmann and K. von Benda-Beckmann 2000 [1994]: 7).

Two major currents can be identified in sociocultural studies on risk. One focuses on the ways in which groups and individuals 'classify, mobilize, and intervene against the threat of loss or the potential of vulnerability to loss' (Zaloom 2004: 366). The other raises questions of planning and control in dealing with the uncertainties that have emerged from the disjuncture between past and present. The contributions to this special section tackle both subjects from a micro-level perspective, thus allowing deep insights into the complex ways in which people anticipate and deal with risk and uncertainty in the contemporary era. 


\section{Coping with Life's Indeterminacies}

Building on in-depth and long-term ethnographic fieldwork, the articles in this special section offer insights into the challenges and ruptures that shape the everyday lives of ordinary people in China (Zavoretti), Vietnam (Endres, Nguyen), Indonesia (Slama) and Lebanon (Schiocchet). Overall, the five case studies reveal that local responses to and strategies of coping with risk and uncertainty are multidimensional, interwoven and guided by social, economic and moral considerations. They thus underline Boholm's point that risk should be seen as a polysemic and polythetic category rather than one that involves a defining set of features (Boholm 1996, in Skinner 2000: 162). This understanding enables an approach more attentive to the complexities of risk perception and risk management in different social and cultural settings.

Recent research has contributed to new insights concerning the role of social relations and support mechanisms in alleviating economic insecurity, human suffering and the shortcomings of state welfare systems (e.g., Schlecker and Fleischer 2013). In these studies, social support is looked at not simply as problem-solving practices directed towards satisfying the needs and aspirations of group members, but as 'something aimed at maintaining relatedness [and] sharing feelings' (Schlecker 2013: 6).

Kinship and family ties have often been studied as a priori systems of social support. In many parts of the world, including Asia, success in overcoming an existential crisis largely depends on a person's ability to mobilize a strong family and kin network. However, as Roberta Zavoretti shows here in her contribution to this issue, for many Chinese citizens the question of starting a family has turned into a crisis in its own right. Young people in contemporary China have come under enormous pressure to improve their suzhi, or 'quality', and cultivate 'into an educated, modern, high-quality citizen' (Jacka 2009: 525) in order to compete not only for employment opportunities, but also in the marriage market. The combined effects of China's demographic imbalance caused by the one-child policy, the unevenness of economic development and the resulting increase in social and class differentiation have been contributing to a marriage crisis that equally (albeit in different ways) affects male and female spouse-seekers. During her research in the city of Nanjing, Zavoretti has observed numerous 'matchmaking gatherings' in public parks that were predominately attended by parents in search of a suitable marriage partner for their adult children. Comparing the anxieties of these young people with the experiences of their parents' generation who grew up during the Maoist period of secure, state-allocated jobs, Zavoretti points out the common threads in their struggles to embody state-envisioned ideals of personhood. Despite intergenerational tensions that arise from different expectations and ambitions, the article reveals that marriage has remained not only an obligatory institution in Chinese society, but also a central prerequisite of social status and material security.

Martin Slama's contribution provides insights into a very different form of marriage crisis faced by the Muslim Hadhrami diaspora in urban Indonesia. Since the end of the period of male-dominated migration flows from the Hadhramaut to Southeast Asia, current generations of Hadhrami women have found it difficult to adhere to traditional marriage rules prescribing endogamous unions not only within the patrilineal Hadhrami community, but also within the same social category. These rules have, in past and present, been at the centre of much anger and debate, and triggered 
a crisis that resulted in a schism of the diaspora. With the improvement of educational standards in Indonesian society since the 1970s, Hadhrami women have attained high levels of economic and intellectual autonomy. This, as Slama elaborates through the example of a well-educated, unmarried Hadhrami business woman, has ramifications for the marriage issue as well. The fact that young Hadhrami women may no longer feel compelled to conform to the strict marriage rules imposed by tradition, Slama argues, may trigger a crisis that could indicate a turning point in the history and identity of the Hadhrami diasporic community at large.

Slama's research resonates well with new directions in kinship studies that emphasize flexibility and negotiation rather than structure and function, thus challenging previous notions of kinship as a given set of normative categories (Carsten 2000; McKinnon and Canell 2013). These shifts in theoretical perspective have likewise opened up avenues of looking at social support as one possible arena of negotiating kinship relations and the various kin ideologies that inform them (e.g., of hierarchy/equality, duty/obligation, reciprocity/exchange).

Within this framework, Minh Nguyen's contribution explores the lives of migrant female domestic workers in Vietnam's capital, Hanoi. Examining their biographic narratives, Nguyen shows that some of these women practice a form of fictitious kinship in the homes of their urban middle-class employers through cultivating intimate relationships with certain family members. This takes place not only on account of their attempts to highlight the affective qualities of their labour, but also because of their efforts to carve out a personal space for themselves away from their rural homes, which they feel are oppressive or lacking in intimacy. Those women who are particularly invested in fictitious kinship, Nguyen argues, are the ones who have experienced disenchantment, disruptions and even traumas in their private and home lives. Fictitious kinship thus helps them to address their own emotional needs while countering the uneasiness of being at work in the intimate home space of others. Yet, rather than blurring class boundaries and leading to employment security, this practice produces new forms of disruptions and uncertainties with regard to the domestic workers' gendered selves and their social status. As they navigate between their rural homes and the world of the urban middle class, such disruptions and uncertainties both perpetuate their vulnerabilities and generate opportunities for transforming their social, gender and class identities.

The new urban class distinctions also become apparent in the social-spatial transformations currently underway in urban Vietnam. As elsewhere in Asia (and beyond), the creation of upscale spaces of lifestyle and consumption for high-end consumers often entails the exclusion of the urban poor and other 'uncivilized' subjects from public visibility. Kirsten Endres attends to this issue by examining how the economic viability of small-scale traders in Hanoi has been affected by urban planning initiatives that include the upgrading of old-style public markets into privately-held luxury shopping malls. Drawing on David Harvey's notion of 'accumulation by dispossession', Endres shows that such processes impact on mobile street vendors and stallholders in permanent markets in different ways. Although the market traders in her case study were allocated vending spaces in the new mall, their unfavourable relocation into the basement of the building and the heightened stall rental fees and electricity bills exposed them to reduced incomes and increased economic uncertainty. 
Mobile vendors, on the other hand, despite being banned from many of Hanoi's streets and thus highly vulnerable to harassment and eviction by the authorities, manage to persist due to their spatial flexibility, and some even profit from the 'downgrading' of the market stallholders portrayed by Endres. The article thus underlines the fact that spatial transformations are always in the making and neither entirely certain nor predictable in their outcome.

Times of economic and/or political ruptures inevitably challenge ethical and moral standards, values and boundaries. Theoretical and empirical studies have elaborated on the interlinkages between risk/uncertainty and trust/trustworthiness and highlighted their importance in establishing reciprocal and negotiated exchange relationships (Molm et al. 2009). Leonardo Schiocchet's research among Palestinian refugee camp dwellers in Lebanon reveals that the uncertainty inherent in the lives of refugees generates a structural disposition towards mistrust and suspicion. In this context, camp dwellers develop unique entrustment practices (i.e., practices of establishing trust as a necessary precondition for social bonding) that give shape to local 'economies of trust' based on familial, religious, ethnic and political ties, but most importantly on honour and moral commitment. Schiocchet defines these entrustment practices as boundary maintenance mechanisms through which camp dwellers forge their identities as refugees in a liminal space where their identities as religious, national, ethnic or political subjects ultimately remain contested, if not denied.

\section{Notes}

1. The articles in this special section are the outcome of a workshop organized jointly in Vienna by the Max Planck Institute for Social Anthropology, Minerva Research Group, Halle/Saale and the Institute for Social Anthropology (ISA), Austrian Academy of Sciences, Vienna in December 2013. Additional support came from the Elise Richter Project, Austrian Science Funds (FWF). The case studies presented here reflect the regional emphases of the research groups involved (MPI participants: East and Southeast Asia; Institute for Social Anthropology, Vienna: Islamic Middle East, Central and Southeast Asia). An edited volume covering a wider range of issues is currently in preparation.

2. Since the 1980s, risk has become a major topic of research in the social sciences. Whereas for Giddens (1991) and Beck (1992), risk has emerged as a defining feature and organizing principle of late modernity, Douglas and Wildavsky (1982) pay particular attention to the cultural dimensions of risk perception and risk management. For a detailed discussion of the risk literature in the social sciences see Lupton (1999, 2013), Caplan (2000) and Zinn (2004).

\section{References}

Beck, U. 1992. Risk Society: Towards a New Modernity. London: Sage.

Benda-Beckmann von, F., \& K. von Benda-Beckmann. 2000 [1994]. Coping with Insecurity. In Coping with Insecurity: An 'Underall' Perspective on Social Security in the Third World (eds) F. von Benda-Beckmann, K. von Benda-Beckmann \& H. Marks, 7-31. Indonesia \& The Netherlands: Pustaka Pelajar \& Focaal Foundation.

Boholm, A. 1996. Risk Perception and Social Anthropology: Critique of Cultural Theory. Ethnos 61(1-2): 64-84.

Boholm, A. 2003. The Cultural Nature of Risk: Can There Be an Anthropology of Uncertainty? Ethnos 68(2): 159-178.

Caplan, P. (ed.) 2000. Risk Revisited. London: Pluto Press. 
Carsten, J. 2000. Cultures of Relatedness: New Approaches to the Study of Kinship. Cambridge: Cambridge University Press.

Douglas, M., \& A. Wildavsky. 1982. Risk and Culture. Berkeley: University of California Press.

Giddens, A. 1991. Modernity and Self-Identity: Self and Society in the Late Modern Age. Cambridge: Polity Press.

Giddens, A. 1997. The Consequences of Modernity. Stanford: Stanford University Press.

Greenhouse, C.J. 2002. Introduction: Altered States, Altered Lives. In Ethnography in Unstable Places: Everyday Lives in Contexts of Dramatic Political Change (eds.) C.J. Greenhouse, E.M. Mertz \& K.B. Warren, 1-36. Durham: Duke University Press.

Jacka, T. 2009. Cultivating Citizens: Suzhi (Quality) Discourse in the PRC. Positions 17(3): 523-535.

Knight, F.H. 1964 [1921]. Risk, Uncertainty and Profit. New York: A.M. Kelley.

Koselleck, R. 2006. Crisis. Journal of the History of Ideas 67(2): 358-400.

Lupton, D. 1999. Risk and Sociocultural Theory. New Directions and Perspectives. Cambridge: Cambridge University Press.

Lupton, D. 2013. Risk: Second Edition. Abingdon: Routledge.

McKinnon, S., \& F. Cannell (eds) 2013. Vital Relations: Modernity and the Persistent Life of Kinship. Santa Fe: SAR Press.

Molm, L, D. Schaefer \& J. Collett. 2009. Fragile and Resilient Trust: Risk and Uncertainty in Negotiated and Reciprocal Exchange. Sociological Theory 27(1): 1-32.

Roitmann, J. 2014. Anti-Crisis. Durham: Duke University Press.

Roy, E. 2007. Modern Crises and Traditional Strategies: Local Ecological Knowledge in Island Southeast Asia. New York: Berghahn Books.

Samimian-Darash, L. 2013. Governing Future Potential Biothreats: Toward an Anthropology of Uncertainty. Current Anthropology 54(1): 1-22.

Schlecker, M. 2013. Introduction. In Ethnographies of Social Support (eds) M. Schlecker \& F. Fleischer, 1-16. New York: Palgrave Macmillan.

Schlecker, M., \& F. Fleischer (eds.). 2013. Ethnographies of Social Support. New York: Palgrave Macmillan.

Skinner, J. 2000. The Eruption of Chances Peak, Montserrat, and the Narrative Containment of Risk. Risk Revisited (ed.) P. Caplan, 156-183. London: Pluto Press.

Vigh, H. 2008. Crisis and Chronicity: Anthropological Perspectives on Continuous Conflict and Decline. Ethnos 73(1): 5-24.

Zaloom, C. 2004. The Productive Life of Risk. Cultural Anthropology 19(3): 365-391.

Zinn, J. 2004. Literature Review: Sociology and Risk. Canterbury: Working Papers, Social Contexts and Responses to Risk Network (SCAAR), 1.

Kirsten W. Endres is Head of Research Group in the Department 'Resilience and Transformation in Eurasia', Max Planck Institute for Social Anthropology, Halle/Saale. Her recent publications include 'Making Law: Small-scale Trade and Corrupt Exceptions at the Vietnam-China Border', American Anthropologist 116(3), September 2014.

Maria Six-Hohenbalken is Researcher at the Institute for Social Anthropology at the Austrian Academy of Sciences, Vienna. She currently holds a project award within the Elise Richter Programme (Austrian Science Funds), working on memory processes after acts of genocide in Kurdish society. 